\title{
Ameliorative Effect of Zinc Oxide Nanoparticles on Antioxidants and Sperm Characteristics in Streptozotocin-Induced Diabetic Rat Testes
}

\author{
Mohamed Afifi, ${ }^{1,2}$ Omar A. Almaghrabi, ${ }^{1}$ and Naif Mohammed Kadasa ${ }^{1}$ \\ ${ }^{1}$ Department of Biological Sciences, Faculty of Science, University of Jeddah, Jeddah, Saudi Arabia \\ ${ }^{2}$ Department of Biochemistry, Faculty of Veterinary Medicine, Zagazig University, Zagazig, Egypt \\ Correspondence should be addressed to Mohamed Afifi; mama200100@gmail.com
}

Received 7 August 2015; Revised 9 October 2015; Accepted 11 October 2015

Academic Editor: Bo Zuo

Copyright (C) 2015 Mohamed Afifi et al. This is an open access article distributed under the Creative Commons Attribution License, which permits unrestricted use, distribution, and reproduction in any medium, provided the original work is properly cited.

\begin{abstract}
The present study investigated the impact of zinc oxide nanoparticles (ZnONPs) on the oxidative status and sperm characteristics in diabetic rat testicular tissue. Forty male albino rats were used in this study; 10 of them served as a control and 30 rats were injected with a single dose $(100 \mathrm{mg} / \mathrm{kg})$ of streptozotocin intraperitoneally. They were subdivided into diabetic, diabetic $+\mathrm{ZnONPs}(10 \mathrm{mg} / \mathrm{kg}$ B.W.), and diabetic and cotreated with ZnONPs + insulin groups. The sperm count and motility were assessed. The activity and mRNA expression of superoxide dismutase (SOD), catalase (CAT), glutathione peroxidase (GPx), glutathione reductase (GRD), and Glutathion-S-Transferase (GST) were determined in the testicular tissue. Malondialdehyde (MDA) and reduced glutathione (GSH) levels were estimated in the testicular tissue. Sperm count and motility increased in ZnONPs treated diabetic rats. A significant increase in the activity and mRNA expression of SOD, CAT, GPx, GRD, and GST was shown in ZnONPs treated diabetic rats. MDA significantly decreased, while GSH increased in testicular tissue of ZnONPs treated diabetic rats. It was concluded that ZnONPs either alone or in combination with insulin have the ability to increase the sperm count and motility and protect the testicular tissue against the oxidative stress induced by diabetes in rats.
\end{abstract}

\section{Introduction}

Diabetes mellitus is a group of metabolic diseases characterized by increase of blood glucose level [1]. The large patient numbers and the consequences of the disease push many scientists to develop several therapies which are costly to a large limit. The most common consequence of diabetes mellitus is the generation of reactive oxygen species (ROS) [2]. ROS can induce $\beta$-cell failure and develop insulin resistance [3]. Diabetes mellitus can directly affect male fertility through the generation of an oxidative stress. The subfertility prevalence rate was high (51\%) among diabetic patients [4]. It is well known that DM induces an adverse change in sperm number, quality, and function [5]. Additionally, DM adversely affects male fertility at many levels, including ejaculation, endocrine control of spermatogenesis, erection, semen volume, and spermatozoa vitality and motility [6]. Type
1 diabetic adolescents had semen of low volume, motility, altered morphology, and high fructose and glucose levels, indicating that ineffective metabolic control was the cause of these alterations [7]. The key mechanism is illustrated as an increase in mitochondrial glucose oxidation which was induced by hyperglycemia, releasing a huge amount of superoxide and other free radicals into the cytoplasm [8]. The recent reports mentioned that the prolonged hyperglycemia produces advanced glycation end-products (AGE) which induce superoxide generation [9]. $\mathrm{Zn}$ has been reported to play a direct role in glucose homeostasis through enhancing hepatic glycogenesis through its actions on the insulin signaling pathway and thus it improves glucose utilization [10]; it inhibits intestinal glucose absorption [11] and increases glucose uptake in skeletal muscle and adipose tissue [10]. Moreover, $\mathrm{Zn}$ is reported to inhibit glucagon secretion [12], thus reducing gluconeogenesis and glycogenolysis; it also 
enhances the structural integrity of insulin [13]. Decreased $\mathrm{Zn}$ in the pancreas may reduce the ability of the islet $\beta$ cells to synthesize and lead insulin in the blood [14]. Furthermore, knowing zinc's antioxidant role [15], reduced $\mathrm{Zn}$ may exacerbate the oxidative stress-mediated complications of diabetes. The pivotal role of $\mathrm{Zn}$ in diabetes mellitus was discovered by supplementation studies in diabetic rats [16]. Several $\mathrm{Zn}$ complexes have been synthesized and proven to be effective in rodent models of diabetes [17]. Recently there has been a huge development of nanotechnology in the science and technology field; metallic nanoparticles, like gold, silver, iron, $\mathrm{Zn}$, and metal oxide nanoparticles, have shown great challenges in the field of medicine and its applications [18]. In a previous study, we proved the antidiabetic effect of ZnONPs and SNPs as a novel agent to control diabetes mellitus in rats [19]. The aim of the study is to test the ability of $\mathrm{ZnONPs}$ to reduce the oxidative stress induced by diabetes mellitus in testicular tissues of diabetic rats and study the possible ameliorative effects of $\mathrm{ZnONPs}$ against diabetesrelated sperm quality.

\section{Materials and Methods}

2.1. Animals. Forty male albino (Sprague-Dawley) rats with average age and weight at the beginning of the experiment $(20 \pm 2$ weeks and $120 \pm 20 \mathrm{~g})$ were used in the study. Rats were housed with each other in the animal house at the Faculty of Science, King Abdulaziz University, for 7 days before the start of the experimental procedures. All rats were grouped into four groups; the first one is control $(N=10)$; it was not subjected to any treatment. The remaining thirty animals were induced to be diabetic through intraperitoneal injection of a single dose $(100 \mathrm{mg} / \mathrm{kg})$ of streptozotocin (STZ) supplied by Sigma-Aldrich (Catalog no. S0130 SIGMA, Germany). The diabetic rats were further divided into four groups; rats of diabetic group $(N=10)$ served as a positive control with no treatment; rats of diabetic $+\mathrm{ZnONPs}$ group were administered $10 \mathrm{mg} / \mathrm{kg} /$ day of ZnONPs per OS; and rats of diabetic + ZnONPs + insulin group were administered a daily dose of ZnONPs (10 mg/kg) and were injected subcutaneously with insulin in a dose of 1.2 units/100 g/day for 30 constitutive days [19].

2.2. Ethical Statement. All experimental procedures were performed in agreement with King Abdulaziz University's experimental animal ethics.

2.3. Diabetes Mellitus Induction. DM was induced by a single intraperitoneal injection of STZ (100 mg/kg) [19]. Rats were fed on a rat formulated diet \{basal rat diet (65.5\%), sucrose $(20 \%)$, and margarine $(10 \%)\}$. Fasting blood glucose was monitored in the blood of the injected rats after $48 \mathrm{~h}$ from the injection. Rats of fasting blood glucose level more than $300 \mathrm{mg} / \mathrm{dL}$ were used as diabetic rats.

2.4. Sampling Protocol. Rats were anesthetized with ketamine and xylazine $(150 \mathrm{mg} / \mathrm{kg}$ and $10 \mathrm{mg} / \mathrm{kg}$, resp.); testes were collected from animals of all experimental groups. The testicular tissue was divided into different aliquots which were preserved at $-80^{\circ} \mathrm{C}$ until their use in biochemical and molecular biological investigations.

2.5. Epididymal Sperm Preparation and Analysis. Rats were anesthetized with ketamine and xylazine $(150 \mathrm{mg} / \mathrm{kg}$ and $10 \mathrm{mg} / \mathrm{kg}$, resp.). The code epididymis was dissected and placed in $1 \mathrm{~mL}$ of prewarmed Ham's F10 medium for $30 \mathrm{~min}$. Gentle tearing was done to swim out spermatozoa into the culture media. Sperm count $\left(10^{6} / \mathrm{mL}\right)$ and motility were assessed using Makler chamber [20].

2.6. Biochemical Assay. Testicular tissue GSH, CAT, SOD, GPx, GR, and GST activities were determined using the kits (Catalog nos. NWK-GSH01, NWK-CAT01, NWK-SOD01, NWK-GPX01, NWK-GR01, and NWK-GST01) purchased from Northwest Life Science Specialties (NWLSS), Vancouver, Canada. MDA was analyzed by measuring the production of thiobarbituric acid reactive substances (TBARS) using TBARS assay kit (Catalog no. 10009055, Cayman, USA).

2.7. Molecular Analysis. Testicular tissue SOD, CAT, GPx, GRD, and GST gene expressions were quantified using real time PCR. Total RNA was isolated from tissue samples using the RNeasy Mini Kit Qiagen (Catalog no. 74104). $0.5 \mu \mathrm{g}$ of total RNA was used for production of cDNA using Qiagen Long Range 2 Step RT-PCR Kit (Catalog no. 205920). Five $\mu \mathrm{L}$ of total cDNA was mixed with $12.5 \mu \mathrm{L}$ of $2 \mathrm{x}$ SYBR Green PCR mix with ROX from BioRad and $10 \mathrm{pmol} / \mu \mathrm{L}$ of each forward and reverse primer for the measured genes. The house keeping gene $\beta$-actin was used as a constitutive control for normalization. Primers were designed using Primer3 software (http://bioinfo.ut.ee/primer3/) as per the published rat SOD, CAT, GPx, GRD, and $\beta$-actin gene sequences (Table 1) of NCBI database; all primaries were provided by Sigma-Aldrich (Sigma-Aldrich Chemie GmbH, Steinheim, Germany). PCR reactions were carried out in ABI PRISM 7300 (Applied Biosystems, USA). The RNA concentration in each sample was determined from the threshold cycle $(\mathrm{Ct})$ values. The mRNA expression levels were calculated relative to $\beta$-actin gene's mRNA levels using $2^{-\mathrm{DDCT}}$ method.

2.8. Statistical Analysis. The obtained data were analyzed using SPSS version 20 (IBM, 1 New Orchard Road, Armonk, New York 10504-1722, United States). Data were presented as mean $\pm \mathrm{SD}(N=10)$. Comparison among groups was made by one-way analysis of variance (ANOVA). Duncan's test was used for testing the intergrouping homogeneity. Statistical significance was set at $p<0.05$.

\section{Results}

3.1. Effect of ZnONPs on Sperm Count and Motility. Effect of ZnONPs on sperm count and motility was shown in Table 2. Our result reported that the sperm count was $46.9 \%$ lower in the diabetic group than in control rats. The total sperm count in the diabetic group was $57.5 \pm 4.5$ million/mL, which was significantly lower than the control 
TABle 1: Primers oligonucleotide sequences of SOD, CAT, GPx, GR, and $\beta$-actin genes.

\begin{tabular}{|c|c|c|c|c|}
\hline Gene & & Oligonucleotides sequences & Size (bp) & Gene ID \\
\hline \multirow{2}{*}{ SOD } & $\mathrm{F}$ & $5^{\prime}$-TCACTTCGAGCAGAAGGCAA-3' & \multirow{2}{*}{221} & \multirow{2}{*}{ NM_017050.1 } \\
\hline & $\mathrm{R}$ & $5^{\prime}$-CCTTTCCAGCAGCCACATTG-3' & & \\
\hline \multirow{2}{*}{ CAT } & $\mathrm{F}$ & $5^{\prime}$-ATGGCTATGGCTCACACACC-3' & \multirow{2}{*}{507} & \multirow{2}{*}{ NM_012520.2 } \\
\hline & $\mathrm{R}$ & $5^{\prime}$-GAGCACGGTAGGGACAGTTC-3' & & \\
\hline \multirow{2}{*}{ GPx } & $\mathrm{F}$ & 5'-GCTCACCCGCTCTTTACCTT-3' & \multirow{2}{*}{387} & \multirow{2}{*}{ M21210.1 } \\
\hline & $\mathrm{R}$ & $5^{\prime}$-AATGGACGAGAACATGCCCA-3' & & \\
\hline \multirow{2}{*}{ GRD } & $\mathrm{F}$ & $5^{\prime}$-CCATGTGGTTACTGCACTTCC-3' & \multirow{2}{*}{171} & \multirow{2}{*}{ NM_053906 } \\
\hline & $\mathrm{R}$ & 5'-GTTCCTTTCCTTCTCCTGAGC-3' & & \\
\hline \multirow{2}{*}{ GST } & $\mathrm{F}$ & $5^{\prime}$-AGCCCTGATTGACATGTACACCG-3' & \multirow{2}{*}{284} & \multirow{2}{*}{ NM_017013.4 } \\
\hline & $\mathrm{R}$ & 5'-AGGCCTTCAGCAGAGGGAAA-3' & & \\
\hline \multirow{2}{*}{$\beta$-actin } & $\mathrm{F}$ & $5^{\prime}$-TCACTATCGGCAATGTGCGG-3' & \multirow{2}{*}{260} & \multirow{2}{*}{ NM_007393 } \\
\hline & $\mathrm{R}$ & $5^{\prime}$-GCTCAGGAGGAGCAATGATG-3' & & \\
\hline
\end{tabular}

TABLE 2: Effect of zinc oxide nanoparticles and insulin on sperm analysis and serum testosterone level in streptozotocin-induced diabetic rat.

\begin{tabular}{|c|c|c|c|c|}
\hline Parameters & Control & Diabetic & Diabetic + ZnONPs & Diabetic $+\mathrm{ZnONPs}+$ insulin \\
\hline Count (million/mL) & $108.3 \pm 5.7^{\mathrm{a}}$ & $57.5 \pm 4.5^{\mathrm{c}}$ & $93.5 \pm 9.3^{\mathrm{b}}$ & $98.8 \pm 3.8^{\mathrm{ab}}$ \\
\hline Rapid motility (\%) (grade a) & $44.45 \pm 3.6^{\mathrm{a}}$ & $6 \pm 0.05^{c}$ & $37.1 \pm 2.8^{\mathrm{b}}$ & $42 \pm 4.4^{\mathrm{a}}$ \\
\hline Slow motility (\%) (grade b) & $13.55 \pm 0.5^{\mathrm{b}}$ & $18.7 \pm 2.6^{\mathrm{a}}$ & $15 \pm 1.3^{\mathrm{b}}$ & $15 \pm 0.8^{\mathrm{b}}$ \\
\hline Nonprogressive motility (\%) (grade c) & $22.4 \pm 5.7$ & $23 \pm 2.2$ & $23 \pm 2.8$ & $22 \pm 1.6$ \\
\hline Immotile sperm (\%) (grade d) & $20 \pm 1.6^{\mathrm{b}}$ & $53.3 \pm 7^{\mathrm{a}}$ & $24.9 \pm 2^{\mathrm{b}}$ & $21 \pm 2^{\mathrm{b}}$ \\
\hline Motility (\%) & $80 \pm 9.8^{\mathrm{a}}$ & $47.7 \pm 4.9^{c}$ & $75.1 \pm 6.9^{\mathrm{b}}$ & $79 \pm 6.8^{\mathrm{a}}$ \\
\hline Serum testosterone (ng/dL) & $5.7 \pm 1.6^{\mathrm{a}}$ & $2.6 \pm 0.8^{\mathrm{b}}$ & $5 \pm 1.6^{\mathrm{a}}$ & $6.2 \pm 1.4^{\mathrm{a}}$ \\
\hline
\end{tabular}

Each point represents the mean $\pm D$ from triplicate determinations ( $n=10$ rats per group). Means within the same row carrying different superscripts (a, $b$, and c) are significant at $p<0.05$.

count $(108.3 \pm 5.7 \mathrm{million} / \mathrm{mL})$. Thirty-day treatment with $\mathrm{ZnONPs}$ at $10 \mathrm{mg} / \mathrm{kg} /$ day produced a significantly increased count $(38.5 \%)$ as compared to diabetic rats. Administration of $\mathrm{ZnONPs}+$ insulin produced $41.8 \%$ higher count when compared to diabetic rats. No significant changes in the sperm count were investigated between rats administrated $\mathrm{ZnONPs}$ alone or in combination with insulin. The grade a and total sperm motility in diabetic rats were 86.5 and $40.3 \%$ lower than those in normal control rats. Meanwhile the immotile sperm (grade d) in the diabetic group was $62.4 \%$ higher than that in the control group. Thirty-day treatment with ZnONPs produced a significantly higher forward and total sperm motility (83.8\% and $36.4 \%$, resp.) when compared to the diabetic group. Meanwhile ZnONPs + insulin produced 85.7 and $39.6 \%$ higher progressive and total sperm motility when compared to the diabetic group. $\mathrm{ZnONPs}+$ insulin were more effective than ZnONPs alone in increasing the progressive and total sperm motility in diabetic rats.

3.2. Effect of ZnONPs on Testosterone Levels in Diabetic Rats. Our result reported that the serum testosterone level decreased in diabetic rats as compared with control rats. Administration of $\mathrm{ZnONPs}$ to the diabetic rats for 30 days resulted in a significant increase in the serum testosterone level when compared to the diabetic nontreated group. Serum testosterone levels in diabetic treated groups returned significantly to approximate levels of the control group. Treatment with ZnONPs alone or in combination with insulin approximated serum testosterone levels as the control.

3.3. Effect of ZnONPs on Testicular Tissue MDA Levels. Our result reported that (Table 3) the MDA concentration in testicular tissue of the diabetic rats was 4.7 times higher than that in control nondiabetic rats. Thirty-day treatment with $\mathrm{ZnONPs}$ at $10 \mathrm{mg} / \mathrm{kg} /$ day caused a significant decreased MDA concentration (69.6\%) when compared to diabetic rats. Administration of ZnONPs + insulin to the diabetic rats produced $76.8 \%$ decreased MDA level when compared to diabetic rats.

3.4. Effect of ZnONPs on Testicular Tissue Antioxidant Gene Expression. Our result showed that the mRNA levels of SOD, CAT, GPx, GR, and GST in testicular tissue of the diabetic rats were significantly lower than those in control nondiabetic rats. Thirty-day treatment with ZnONPs at $10 \mathrm{mg} / \mathrm{kg} / \mathrm{day}$ caused a significant increase of SOD, CAT, GPx, GR, and GST mRNA expression levels when compared to the diabetic group. ZnONPs + insulin were more effective than ZnONPs alone in increasing the SOD, CAT, GPx, GR, and GST mRNA expression levels in diabetic rats (Table 4).

3.5. Effect of ZnONPs on Testicular Tissue Antioxidant Enzyme Activities. Our result showed that (Table 3) the GSH level and 
TABLE 3: Biochemical investigations in experimental rats administered zinc oxide nanoparticles.

\begin{tabular}{|c|c|c|c|c|}
\hline Parameters & Control & Diabetic & Diabetic $+\mathrm{ZnONPs}$ & Diabetic + ZnONPs + insulin \\
\hline MDA (nmol/g tissue) & $1.2 \pm 0.06^{\mathrm{b}}$ & $5.6 \pm 0.5^{\mathrm{a}}$ & $1.7 \pm 0.3^{\mathrm{b}}$ & $1.3 \pm 0.05^{\mathrm{b}}$ \\
\hline GSH ( $\mu \mathrm{mol} / \mathrm{g}$ tissue $)$ & $123 \pm 4^{\mathrm{ab}}$ & $40 \pm 2^{c}$ & $121 \pm 8^{\mathrm{b}}$ & $131 \pm 4^{\mathrm{a}}$ \\
\hline SOD $(\mu \mathrm{g} / \mathrm{g}$ tissue $)$ & $55.7 \pm 3.2^{\mathrm{a}}$ & $24 \pm 2.6^{\mathrm{c}}$ & $47.3 \pm 2.5^{\mathrm{b}}$ & $56.7 \pm 3.5^{\mathrm{a}}$ \\
\hline CAT $\left(\mu \mathrm{MH}_{2} \mathrm{O}_{2}\right.$ decomposed/g tissue $)$ & $1043 \pm 51^{\mathrm{a}}$ & $223 \pm 25^{\mathrm{c}}$ & $943 \pm 40^{\mathrm{b}}$ & $1110 \pm 36^{\mathrm{a}}$ \\
\hline $\mathrm{GPx}(\mu \mathrm{M} / \mathrm{min} / \mathrm{g}$ tissue $)$ & $166.7 \pm 15^{\mathrm{a}}$ & $35.7 \pm 5^{\mathrm{b}}$ & $161 \pm 7^{\mathrm{a}}$ & $173 \pm 12^{\mathrm{a}}$ \\
\hline GRD (unit/g tissue) & $15.7 \pm 2^{\mathrm{ab}}$ & $2.9 \pm 0.9^{c}$ & $13 \pm 2^{\mathrm{b}}$ & $16.1 \pm 0.8^{\mathrm{a}}$ \\
\hline GST ( $\mu \mathrm{mol}$ GSHCDNB conjugate/min/mg protein) & $86 \pm 3.5^{\mathrm{ab}}$ & $26 \pm 4^{\mathrm{c}}$ & $81 \pm 6^{\mathrm{b}}$ & $92 \pm 2.5^{\mathrm{a}}$ \\
\hline
\end{tabular}

Each point represents the mean $\pm D$ from triplicate determinations ( $n=10$ rats per group). Means within the same row carrying different superscripts (a, $\mathrm{b}$, and c) are significant at $p<0.05$.

TABLE 4: Effect of zinc oxide nanoparticles on the mRNA expression profile (fold of change relative to the control group) of antioxidant genes in streptozotocin-induced diabetic rat testes.

\begin{tabular}{lcccc}
\hline Genes & Control & Diabetic & Diabetic + ZnONPs & Diabetic + ZnONPs + insulin \\
\hline SOD & $1 \pm 0.01^{\mathrm{a}}$ & $0.15 \pm 0.02^{\mathrm{b}}$ & $0.99 \pm 0.09^{\mathrm{a}}$ & $1.12 \pm 0.15^{\mathrm{a}}$ \\
CAT & $1.07 \pm 0.02^{\mathrm{b}}$ & $0.22 \pm 0.02^{\mathrm{c}}$ & $1.04 \pm 0.02^{\mathrm{b}}$ & $1.7 \pm 0.25^{\mathrm{a}}$ \\
GPx & $1.06 \pm 0.02^{\mathrm{b}}$ & $0.30 \pm 0.09^{\mathrm{c}}$ & $1.06 \pm 0.02^{\mathrm{b}}$ & $3.3 \pm 0.87^{\mathrm{a}}$ \\
GR & $1.05 \pm 0.03^{\mathrm{b}}$ & $0.29 \pm 0.08^{\mathrm{c}}$ & $1.4 \pm 0.26^{\mathrm{b}}$ & $4 \pm 0.6^{\mathrm{a}}$ \\
GST & $0.94 \pm 0.03^{\mathrm{b}}$ & $0.13 \pm 0.02^{\mathrm{c}}$ & $1.06 \pm 0.03^{\mathrm{b}}$ & $1.76 \pm 0.4^{\mathrm{a}}$ \\
\hline
\end{tabular}

Each point represents the mean $\pm D$ from triplicate determinations ( $n=10$ rats per group). Means within the same row carrying different superscripts (a, $\mathrm{b}$, and c) are significant at $p<0.05$.

SOD, CAT, GPx, GR, and GST activities in testicular tissue of the diabetic rats were significantly lower than those in control nondiabetic rats. Thirty-day treatment with ZnONPs at $10 \mathrm{mg} / \mathrm{kg} /$ day caused a significant increase of GSH level and SOD, CAT, GPx, GR, and GST activities when compared to the diabetic group. ZnONPs + insulin were more effective than ZnONPs alone in increasing the GSH level and SOD, CAT, GPx, GR, and GST activities in diabetic rats.

\section{Discussion}

This study investigated the effect of ZnONPs on sperm count, motility, and oxidative stress in testicular tissue of the diabetic rats. Sperm analysis is useful for determination of the male infertility cause [21]. Our results reported that sperm count and motility lowered in diabetic rats, while the dead sperm increased. Many mechanisms explained this finding including the hormonal impairment of follicle-stimulating hormone (FSH), luteinizing hormone (LH), and testosterone. The oxidative stress induced by hyperglycemia and formation of advanced glycation end-products (AGE) was incriminated in the bad effect of diabetes on sperm [22]. The effect of diabetes on sperm count and motility was consistent with other investigations in both humans and rats [23]. Short-term hyperglycemia was adversely affecting the sperm count in diabetic rats [24]. The oxidative stress was incriminated as the cause of the bad effect of prolonged hyperglycemia on sperm count and motility in diabetic rats [25]. The present study proved that treatment of the diabetic rats with $\mathrm{ZnONPs}$ alone or in combination with insulin prevented damage in sperm count and motility; this may be due to the antioxidant characters of ZnONPs [26]. Treatment with ZnONPs produced an increased sperm count, proving that ZnONPs have the ability to protect the sperm from the deleterious effect induced by diabetes. ZnONPs + insulin were more effective than $\mathrm{ZnONPs}$ alone in increasing the progressive and total sperm motility in diabetic rats. The effect of insulin on sperm characteristics was previously documented; insulin and/or glucose effect on the pituitary biosynthesis and/or secretion of FSH was necessary for spermatogenesis [22].

Our result reported that the serum testosterone level was lower in diabetic rats than in control nondiabetic rats. In the same line, Ding et al. [27] showed that men with diabetes had significantly lower levels of serum testosterone when compared with men without diabetes. Brand et al. [28] have shown that diabetic men had not only lower testosterone but also lower levels of sex hormone binding globulin (SHBG) when compared with nondiabetic men. Potential mechanisms for low testosterone levels in type 2 diabetes mellitus include reduced or absent stimulatory effect of insulin on Leydig cells [29], increased leptin levels in diabetes causing Leydig cell dysfunction [30], and increased TNF levels in diabetes inhibiting steroid biosynthesis in Leydig cells [31]. Our finding proved the ability of ZnONPs alone or in combination with insulin to approximately alleviate the bad effect of diabetes on serum testosterone levels. Potential mechanisms for induction of testosterone production in rats administrated $\mathrm{ZnONPs}$ include increased insulin production and sensitivity as proved by our previous work [19]. $\mathrm{Zn}$ increased the release of luteinizing and follicle stimulating hormones from the pituitary gland, which stimulate testosterone production; $\mathrm{Zn}$ 
also inhibits the aromatase enzyme that converts testosterone into excess estrogen [32].

The present investigation pointed to a reduction in GSH levels and SOD, CAT, GPx, GR, and GST activities and gene expressions; meanwhile, the MDA level was increased in diabetic nontreated rats. It is well known that diabetes mellitus has the ability to induce an oxidative stress in many tissues [33]. The increase in mitochondrial glucose oxidation induced by hyperglycemia releases a huge amount of superoxide and other free radicals into the cytoplasm [8]. The recent reports mentioned that the prolonged hyperglycemia produces AGEs, which is the cause of superoxide generation [9]. This activates NADPH oxidase [34], which increases superoxide generation [35]. Diabetes induced a state of oxidative stress, which was evidenced by an increase in levels of MDA and a decrease in SOD and GST activities in testicular tissues [22].

Our findings have further shown that ZnONPs were able to decrease the oxidative stress in testicular tissue as manifested from decreased MDA levels, higher GSH amount, and induced antioxidant enzymes (SOD, CAT, GPx, GR, and GST) activities and gene expressions in the testicular tissue of diabetic rats. We proved the antioxidant ability of ZnONPs in diabetic rat brain tissue. It increased the activity and mRNA expression levels of SOD, CAT, GRD, and GPx and GSH levels and decreased MDA levels in brain tissue of the treated diabetic rats [26]. Potential mechanisms for antioxidant ability of ZnONPs may include the potent antidiabetic effect of ZnONPs; it induced significantly reduced blood glucose, increased serum insulin, and activated glucose oxidation preventing hyperglycemia in diabetic rats [19], which decreases superoxide generated by advanced glycation end-products [9]. The other mechanism may be the increased $\mathrm{Zn}$ concentration in testicular tissue produced from the dissociation of $\mathrm{ZnONPs}$. It is well known that $\mathrm{Zn}$ is a powerful antioxidant metal; it is the core constituent of antioxidant enzymes such as SOD and recognized protector of sulfhydryl groups; it is also thought to impair lipid peroxidation by displacing transition metals such as iron and copper from catalytic sites [36]. $\mathrm{ZnONPs}$ is able to protect cell membrane integrity against oxidative stress damage, increase antioxidant enzyme levels, and decrease MDA level. It can improve antioxidant activity, enhance the activities of antioxidases, and decrease the levels of free radicals [37].

In conclusion, DM has an adverse effect on the antioxidant status of the testicular tissue through induction of lipid peroxidation as represented by increased MDA level; it decreased the gene expression and activity of the antioxidant enzymes such as SOD, CAT, GDR, and GPx. ZnONPs alone or in combination with insulin improved the antioxidant status of the testicular tissue and improved some sperm parameters in diabetic rats.

\section{Conflict of Interests}

The authors declare that there is no conflict of interests regarding the publication of this paper.

\section{Acknowledgment}

This project was funded by the Deanship of Scientific Research (DSR), University of Jeddah, Jeddah, under Grant no. G-1436-965-75. The authors, therefore, acknowledge with thanks DSR technical and financial support.

\section{References}

[1] Y. Lin and Z. Sun, "Current views on type 2 diabetes," Journal of Endocrinology, vol. 204, no. 1, pp. 1-11, 2010.

[2] D. Harrison, K. K. Griendling, U. Landmesser, B. Hornig, and H. Drexler, "Role of oxidative stress in atherosclerosis," American Journal of Cardiology, vol. 91, no. 3, supplement, pp. 7-11, 2003.

[3] J. W. Stephens, M. P. Khanolkar, and S. C. Bain, “The biological relevance and measurement of plasma markers of oxidative stress in diabetes and cardiovascular disease," Atherosclerosis, vol. 202, no. 2, pp. 321-329, 2009.

[4] S. La Vignera, A. E. Calogero, R. Condorelli, F. Lanzafame, B. Giammusso, and E. Vicari, "Andrological characterization of the patient with diabetes mellitus," Minerva Endocrinologica, vol. 34, no. 1, pp. 1-9, 2009.

[5] C. Mallidis, I. Agbaje, N. McClure, and S. Kliesch, "The influence of diabetes mellitus on male reproductive function: a poorly investigated aspect of male infertility," Der Urologe, vol. 50, no. 1, pp. 33-37, 2011.

[6] A. Petroianu, L. R. Alberti, M. Antonio, B. de Melo, and L. M. de Almeida, "Relation between diabet mellitos and male fertility," Einstein, vol. 7, no. 4, pp. 407-410, 2009.

[7] M. G. Alves, A. D. Martins, L. Rato, P. I. Moreira, S. Socorro, and P. F. Oliveira, "Molecular mechanisms beyond glucose transport in diabetes-related male infertility," Biochimica et Biophysica Acta-Molecular Basis of Disease, vol. 1832, no. 5, pp. 626-635, 2013.

[8] J. W. Baynes, "Role of oxidative stress in development of complications in diabetes," Diabetes, vol. 40, no. 4, pp. 405-412, 1991.

[9] C. M. Warboys, H.-B. Toh, and P. A. Fraser, "Role of NADPH oxidase in retinal microvascular permeability increase by RAGE activation," Investigative Ophthalmology \& Visual Science, vol. 50, no. 3, pp. 1319-1328, 2009.

[10] J. Jansen, W. Karges, and L. Rink, "Zinc and diabetes-clinical links and molecular mechanisms," Journal of Nutritional Biochemistry, vol. 20, no. 6, pp. 399-417, 2009.

[11] E. Ueda, Y. Yoshikawa, H. Sakurai, Y. Kojima, and N. M. Kajiwara, "In vitro alpha-glucosidase inhibitory effect of $\mathrm{Zn}$ (II) complex with 6-methyl-2-picolinmethylamide," Chemical and Pharmaceutical Bulletin, vol. 53, no. 4, pp. 451-452, 2005.

[12] L. Egefjjord, A. B. Petersen, A. M. Bak, and J. Rungby, "Zinc, alpha cells and glucagon secretion," Current Diabetes Reviews, vol. 6, no. 1, pp. 52-57, 2010.

[13] Q. Sun, R. M. Van Dam, W. C. Willett, and F. B. Hu, "Prospective study of zinc intake and risk of Type 2 diabetes in women," Diabetes Care, vol. 32, no. 4, pp. 629-634, 2009.

[14] J. A. Meyer and D. M. Spence, "A perspective on the role of metals in diabetes: past findings and possible future directions," Metallomics, vol. 1, no. 1, pp. 32-41, 2009.

[15] S. A. Hussein, Y. A. EL-Senosi, K. El-Dawy, and H. A. Baz, "Protective effect of zinc oxide nanoparticles on oxidative stress in experimental-induced diabetes in rats," Benha Veterinary Medical Journal, vol. 27, no. 2, pp. 405-414, 2014. 
[16] J. U. Ukperoro, N. Offiah, T. Idris, and D. Awogoke, “Antioxidant effect of zinc, selenium and their combination on the liver and kidney of alloxan-induced diabetes in rats," Mediterranean Journal of Nutrition and Metabolism, vol. 3, no. 1, pp. 25-30, 2010.

[17] S. Karmaker, T. K. Saha, Y. Yoshikawa, and H. Sakurai, "A zinc (II)/poly $(\gamma$-glutamic acid) complex as an oral therapeutic for the treatment of type-2 diabetic $\mathrm{KKA}^{y}$ mice," Macromolecular Bioscience, vol. 9, no. 3, pp. 279-286, 2009.

[18] S. M. Hirst, A. Karakoti, S. Singh et al., "Bio-distribution and in vivo antioxidant effects of cerium oxide nanoparticles in mice," Environmental Toxicology, vol. 28, no. 2, pp. 107-118, 2013.

[19] A. Alkaladi, A. M. Abdelazim, and M. Afifi, "Antidiabetic activity of zinc oxide and silver nanoparticles on streptozotocininduced diabetic rats," International Journal of Molecular Sciences, vol. 15, no. 2, pp. 2015-2023, 2014.

[20] A. R. Talebi, E. Mangoli, H. Nahangi, M. Anvari, M. Pourentezari, and I. Halvaei, "Vitamin C attenuates detrimental effects of diabetes mellitus on sperm parameters, chromatin quality and rate of apoptosis in mice," European Journal of Obstetrics Gynecology and Reproductive Biology, vol. 181, pp. 3236, 2014.

[21] N. Giribabu, K. E. Kumar, S. S. Rekha, S. Muniandy, and N. Salleh, "Chlorophytum borivilianum (Safed Musli) root extract prevents impairment in characteristics and elevation of oxidative stress in sperm of streptozotocin-induced adult male diabetic Wistar rats," BMC Complementary and Alternative Medicine, vol. 14, article 291, 2014.

[22] F. A. R. Sawiress, M. S. Ziada, W. S. F. Bebawy, and H. A. Amer, "Effect of ginseng extract supplementation on testicular functions in diabetic rats," Endocrine Regulations, vol. 45, no. 3, pp. 139-148, 2011.

[23] R. Bal, G. Türk, M. Tuzcu et al., "Protective effects of nanostructures of hydrated $\mathrm{C}_{60}$ fullerene on reproductive function in streptozotocin-diabetic male rats," Toxicology, vol.282, no. 3, pp. 69-81, 2011.

[24] W. R. Scarano, A. G. Messias, S. U. Oliva, G. R. Klinefelter, and W. G. Kempinas, "Sexual behaviour, sperm quantity and quality after short-term streptozotocin-induced hyperglycaemia in rats," International Journal of Andrology, vol. 29, no. 4, pp. 482488, 2006.

[25] S. Amaral, A. J. Moreno, M. S. Santos, R. Seiça, and J. RamalhoSantos, "Effects of hyperglycemia on sperm and testicular cells of Goto-Kakizaki and streptozotocin-treated rat models for diabetes," Theriogenology, vol. 66, no. 9, pp. 2056-2067, 2006.

[26] M. Afifi and A. M. Abdelazim, "Ameliorative effect of zinc oxide and silver nanoparticles on antioxidant system in the brain of diabetic rats," Asian Pacific Journal of Tropical Biomedicine, vol. 5, no. 10, pp. 874-877, 2015.

[27] E. L. Ding, Y. Song, V. S. Malik, and S. Liu, "Sex differences of endogenous sex hormones and risk of type 2 diabetes: a systematic review and meta-analysis," The Journal of the American Medical Association, vol. 295, no. 11, pp. 1288-1299, 2006.

[28] J. S. Brand, N. J. Wareham, M. Dowsett et al., "Associations of endogenous testosterone and SHBG with glycated haemoglobin in middle-aged and older men," Clinical Endocrinology, vol. 74, no. 5, pp. 572-578, 2011.

[29] J. Ballester, M. C. Muñoz, J. Domínguez, T. Rigau, J. J. Guinovart, and J. E. Rodríguez-Gil, "Insulin-dependent diabetes affects testicular function by FSH- and LH-linked mechanisms," Journal of Andrology, vol. 25, no. 5, pp. 706-719, 2004.
[30] A. M. Isidori, M. Caprio, F. Strollo et al., "Leptin and androgens in male obesity: evidence for leptin contribution to reduced androgen levels," The Journal of Clinical Endocrinology \& Metabolism, vol. 84, no. 10, pp. 3673-3680, 1999.

[31] C. Y. Hong, J. H. Park, R. S. Ahn et al., "Molecular mechanism of suppression of testicular steroidogenesis by proinflammatory cytokine tumor necrosis factor alpha," Molecular and Cellular Biology, vol. 24, no. 7, pp. 2593-2604, 2004.

[32] N. K. Al-Ani, U. Al-Kawaz, and B. T. Saeed, "Protective influence of zinc on reproductive parameters in male rat treated with cadmium," American Journal of Medicine and Medical Sciences, vol. 5, no. 2, pp. 73-81, 2015.

[33] J.-A. Simoneau, S. R. Colberg, F. L. Thaete, and D. E. Kelley, "Skeletal muscle glycolytic and oxidative enzyme capacities are determinants of insulin sensitivity and muscle composition in obese women," The FASEB Journal, vol. 9, no. 2, pp. 273-278, 1995.

[34] L. Quagliaro, L. Piconi, R. Assaloni, L. Martinelli, E. Motz, and A. Ceriello, "Intermittent high glucose enhances apoptosis related to oxidative stress in human umbilical vein endothelial cells: the role of protein kinase $\mathrm{C}$ and $\mathrm{NAD}(\mathrm{P}) \mathrm{H}$-oxidase activation," Diabetes, vol. 52, no. 11, pp. 2795-2804, 2003.

[35] N. M. Mustapha, J. M. Tarr, E. M. Kohner, and R. Chibber, "NADPH oxidase versus mitochondria-derived ROS in glucose-induced apoptosis of pericytes in early diabetic retinopathy," Journal of Ophthalmology, vol. 2010, Article ID 746978, 10 pages, 2010.

[36] R. J. Aitken and S. D. Roman, "Antioxidant systems and oxidative stress in the testes," Oxidative Medicine and Cellular Longevity, vol. 1, no. 1, pp. 15-24, 2008.

[37] P. Badkoobeh, K. Parivar, S. M. Kalantar, S. D. Hosseini, and A. Salabat, "Effect of nano-zinc oxide on doxorubicin-induced oxidative stress and sperm disorders in adult male Wistar rats," Iranian Journal of Reproductive Medicine, vol. 11, no. 5, pp. 355364, 2013. 

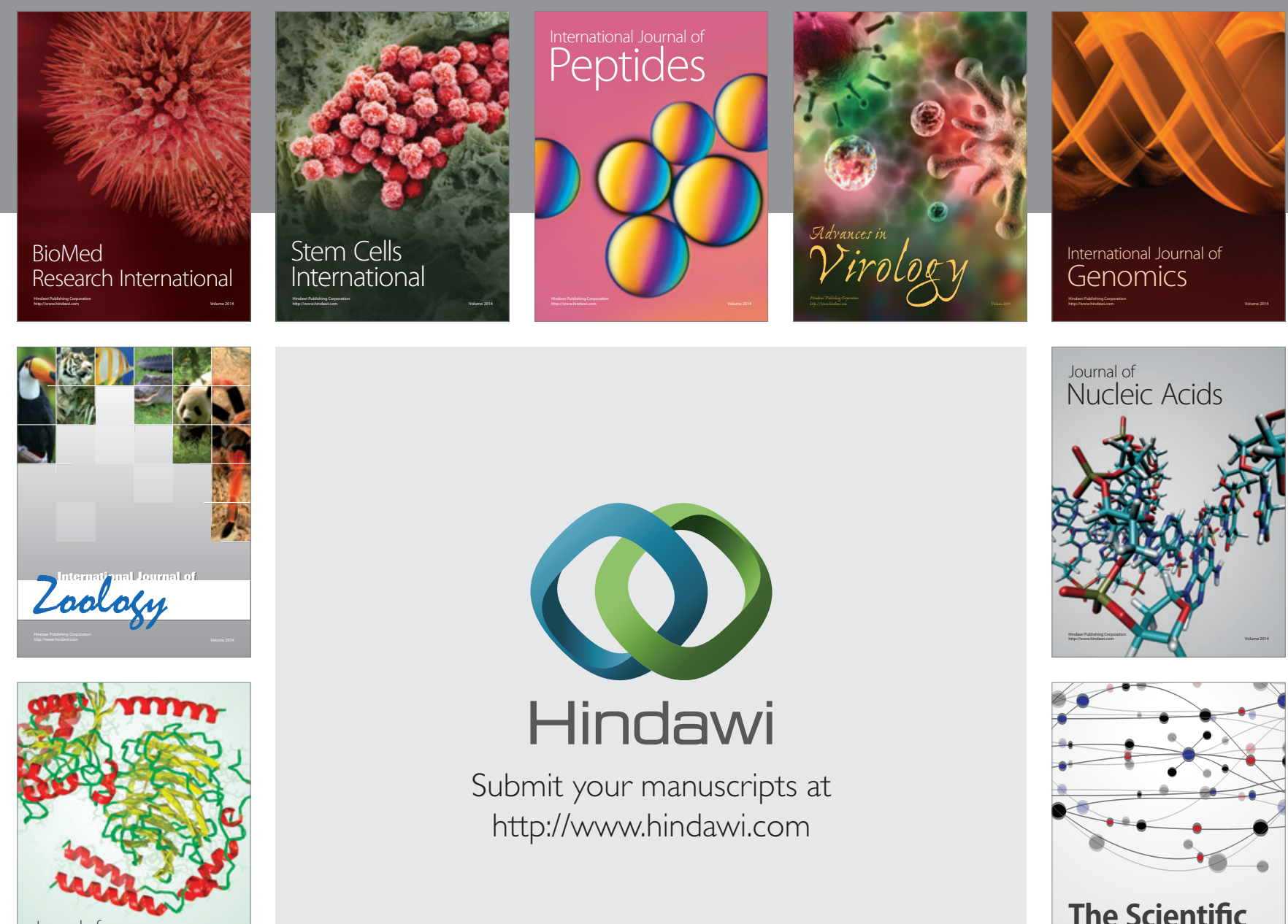

Submit your manuscripts at

http://www.hindawi.com

Journal of
Signal Transduction
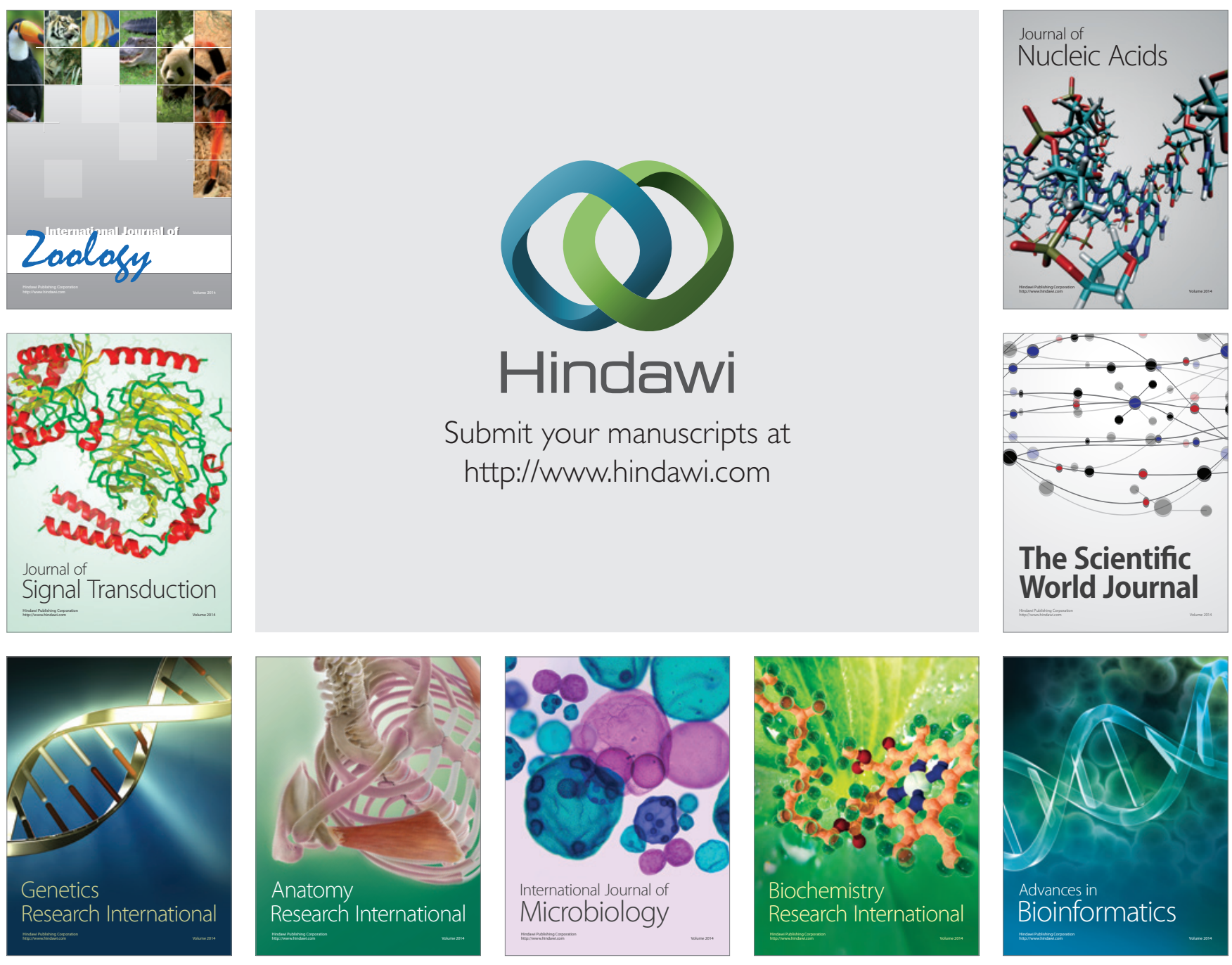

The Scientific World Journal
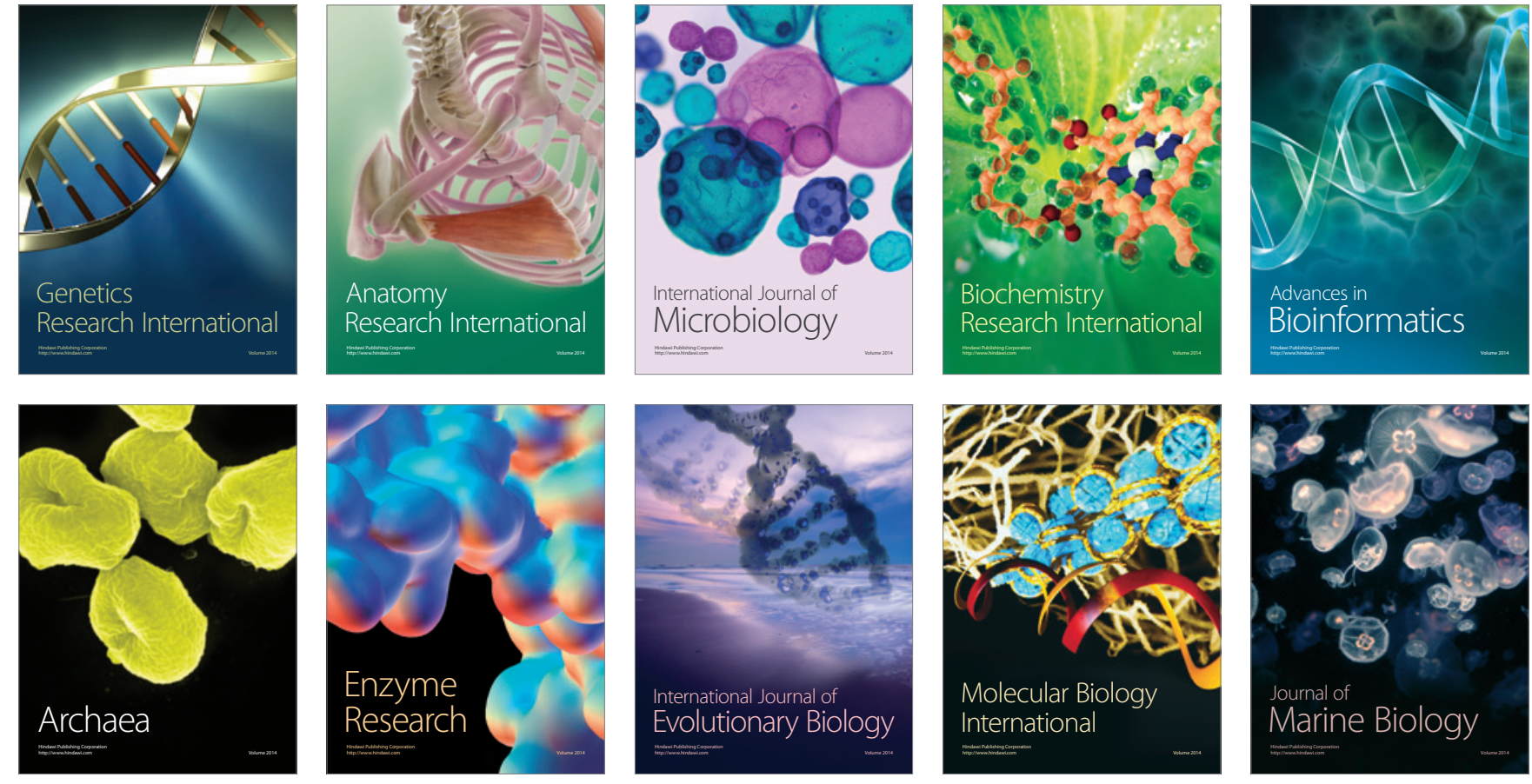